LOOS, R.A.; SILVA, D.J.H.; FONTES, P.C.R.; PICANÇO, M.C.; GONTIJO, L.M.; SILVA, E.M.; SEMEÃO, A.A. Identificação e quantificação dos componentes de perdas de produção do tomateiro. Horticultura Brasileira, Brasília, v.22, n.2, p.238-242, abril-junho 2004.

\title{
Identificação e quantificação dos componentes de perdas de produção do tomateiro $^{1}$
}

\author{
Rodolfo A. Loos²; Derly José H. da Silva²; Paulo Cezar R. Fontes²; Marcelo C. Picanço³; Lessando M. \\ Gontijo $^{3}$; Ézio M. da Silva ${ }^{3}$; Altair Arlindo Semeão ${ }^{3}$ \\ ${ }^{2}$ UFV, Depto. Fitotecnia, 36571-000 Viçosa-MG; E-mail: rudiloos@hotmail.com; ${ }^{3}$ UFV, Depto. Biologia Animal, 36571-000 Viçosa-MG
}

\begin{abstract}
RESUMO
Foram identificados e quantificados, no período de verão-outono, evidenciando o componente crítico e o fator-chave de perdas da cultura, mediante a utilização da tabela de vida das culturas. O trabalho foi realizado na Horta de Pesquisa da UFV, de janeiro a junho de 2001, sob delineamento de blocos casualizados, com dois tratamentos (cultivar Santa Clara I 5300 e híbrido Débora Plus) e cinco repetições. Durante o ciclo da cultura, foram avaliados o número de plantas mortas e as causas de morte, o número de flores e frutos/ planta. Nas colheitas, os frutos sadios foram contados, pesados e classificados, sendo identificadas as causas de perda dos frutos danificados. Observou-se maior influência da perda de plantas $(\mathrm{r}=0,89)$ $(P<0,01)$ sobre as perdas totais sendo, consequentemente, plantas o componente crítico de perdas da cultura. O vírus TSWV foi o único causador de mortes dentro do componente crítico de produção, sendo considerado o fator-chave de perdas da cultura.
\end{abstract}

Palavras-chave: Lycopersicon esculentum Mill., tabela de vida das culturas, vira cabeça do tomateiro, tospovirus, TSWV.

\begin{abstract}
Identification and quantification of tomato yield loss components

The components of loss in tomato production were identified and quantified, in the summer-autumn period. The critial component and the key factor in the cultivation loss become evident using the methodology of the crop life table. The experiment was conducted at the Universidade Federal de Viçosa, Minas Gerais State, Brazil, from January to June 2001 and consisted of two treatments (cultivars Santa Clara and F1 Débora Plus) in a randomized complete block design with 5 replications. During the tomato cycle, the number of dead plants, the causes of this and the number of flowers and fruits/ plant were evaluated. At harvest, the healthy fruits were counted, weighted and classified; the causes of fruit damage were identified and the loss quantified. Total loss was more influenced by the fluctuation of the component plants $(r=0,89)(P<0,01)$ than by other production components; consequently, plants were considered the critical production components of tomato. TSWV virus was the only factor affecting plant death, being considered the key-factor in the loss of this tomato production.
\end{abstract}

Keywords: Lycopersicon esculentum Mill., crop life table, tomato spotted wilt virus, TSWV.

\section{(Recebido para publicação em 6 de setembro de 2003 e aceito em 27 de fevereiro de 2004)}

\begin{abstract}
A produção de tomate é considerada atividade de alto risco, principalmente, devido a grande variedade de ambientes e sistemas nos quais é cultivado, alta suscetibilidade ao ataque de pragas e doenças e exigência em insumos e serviços, acarretando elevado investimento de recursos financeiros por unidade de área.

O tospovírus (Tomato Spotted Wilt Virus) (TSWV) é responsável por uma das mais sérias doenças na cultura do tomateiro (vira-cabeça do tomateiro), devido aos elevados prejuízos econômicos que pode acarretar à cultura (Sinigaglia et al., 2000). O controle desta virose pelo combate ao vetor tornase difícil, porque uma vez infectados, adultos de tripes podem migrar longas
\end{abstract}

distâncias e, rapidamente, transmitirem a doença (Ullman et al., 1997).

Como o desenvolvimento e a produção de uma espécie vegetal dependem do seu genótipo e das condições ambientais, fatores associados ao clima, ao solo e aos métodos de cultivo podem ser responsáveis pela predisposição de plantas ao ataque de pragas e doenças (Bergamim Filho et al., 1995). Freqüentemente, a combinação de vários desses fatores ocasiona maior incidência de perdas. Dessa forma, é essencial identificar e quantificar os fatores de perda na cultura do tomateiro a fim de que se possa produzir com menos riscos e alcançar maior produtividade.

As tabelas de vida são instrumentos empregados em estudos de dinâmica populacional (Silveira Neto et al., 1976), sendo valiosos guias no planejamento das estratégias do manejo de pragas. Quando utilizadas para culturas, conforme Harcourt (1970), Chandler (1984) e Picanço et al. (1998), as tabelas de vida incluem a identificação dos fatores de perdas e a associação destes com o estádio de desenvolvimento da cultura.

Um modelo de estimativa quantitativa das perdas por unidade de área para cada componente de produção foi desenvolvido por Picanço (1992), possibilitando a determinação do componente crítico de perdas de produção (ou seja, aquele que possui maior regulação sobre as perdas ocorridas na cultura) e o fator-chave de perdas (principal causa reguladora de perdas no componente

1 Parte da Dissertação de Mestrado em Fitotecnia do primeiro autor, área de concentração em Técnicas Culturais, pela Universidade Federal de Viçosa (UFV). 
crítico de perdas). Para tanto, foi adaptado o modelo desenvolvido por Varley e Gradwell (1960), que considera como fator-chave aquele cuja variação de perdas específicas apresente maior correlação com a flutuação de perdas totais.

Dessa forma, o objetivo deste trabalho foi identificar e quantificar os componentes de perdas de produção em tomateiro, evidenciando o componente crítico de perdas da cultura e o fatorchave de perdas pela utilização da tabela de vida das culturas.

\section{MATERIAL E MÉTODOS}

O trabalho foi realizado na Horta de Pesquisa da Universidade Federal de Viçosa, em Viçosa (MG), de janeiro a junho de 2001. O experimento foi conduzido sob delineamento experimental de blocos casualizados, constando de dois tratamentos (cultivar Santa Clara I 5300 e híbrido Débora Plus) e cinco repetições. A área da parcela experimental foi $4,8 \mathrm{~m}^{2}$, sendo composta por 8 plantas. A bordadura utilizada foi a de experimento.

As mudas foram produzidas em bandejas de isopor, medindo $68 \times 34 \mathrm{~cm}$, com 128 células e o transplantio feito quando as mudas apresentaram, em média, quatro folhas definitivas, aos 29 dias após o semeio. As mudas foram transplantadas no espaçamento de $1,0 \times 0,6$ $\mathrm{m}$, sendo tutoradas no sistema vertical com fitilho. As plantas foram conduzidas com uma haste e foram despontadas com três folhas acima do sexto racimo (Oliveira, 1993; Camargos, 1998).

O solo do experimento foi arado, gradeado e sulcado e a análise química do solo revelou: $\mathrm{pH}$ em água $=6,0$ (relação 1:2,5); P = 52,6 mg/dm 3 ; $\mathrm{Na}=4,0$ $\mathrm{mg} / \mathrm{dm}^{3} ; \mathrm{K}=27,0 \mathrm{mg} / \mathrm{dm}^{3}$ (P-Na-K: extrator Mehlich 1); $\mathrm{Ca}=3,8 \mathrm{cmol} / \mathrm{dm}^{3}$; $\mathrm{Mg}=0,6 \mathrm{cmol}_{\mathrm{c}} / \mathrm{dm}^{3} ; \mathrm{Al}=2,4 \mathrm{cmol} / \mathrm{dm}^{3}$ (Ca-Mg-Al extrator $\mathrm{KCl} 1 \mathrm{~mol} / \mathrm{L})$; SB $=4,5 \mathrm{cmol} / \mathrm{dm}^{3}$ (extrator acetato de cálcio $0,5 \mathrm{~mol} / \mathrm{L}, \mathrm{pH} 7,0)$; CTC (t) $=4,5$ $\mathrm{cmol}_{\mathrm{c}} / \mathrm{dm}^{3} ;$ CTC $(\mathrm{T})=7,0 \mathrm{cmol}_{\mathrm{c}} / \mathrm{dm}^{3} \mathrm{e}$ $\mathrm{V}=65,1 \%$. No sulco de plantio foi feita a aplicação de 10 t/ha de esterco de galinha, $10 \mathrm{~kg} / \mathrm{ha}$ de ácido bórico, $200 \mathrm{~g} /$ ha de molibdato de sódio e $200 \mathrm{~kg} / \mathrm{ha}$ de sulfato de magnésio. A adubação de cobertura foi feita por fertirrigação com
$240 \mathrm{~kg} / \mathrm{ha}$ de $\mathrm{N}, 700 \mathrm{~kg} / \mathrm{ha}$ de $\mathrm{P}_{2} \mathrm{O}_{5}$ e $800 \mathrm{~kg} /$ ha de $\mathrm{K}_{2} \mathrm{O}$, respectivamente na forma de sulfato de amônio, superfosfato simples e cloreto de potássio, divididos em oito parcelas, realizadas a cada duas semanas.

Para o controle de insetos-praga, utilizou-se o manejo integrado, aplicandose inseticidas somente quando as pragas atingiam o nível de controle (1 vetor/ ponteiro, $20 \%$ de folhas minadas e $5 \%$ de frutos broqueados) (Sinigaglia et al., 2000). Para a prevenção e controle de doenças, como Phytophthora infestans e Alternaria solani, foram feitas aplicações de fungicida, a cada duas semanas.

Foi feito o levantamento da seqüência de mortalidade das plantas, realizado pela anotação semanal do número de plantas mortas, identificando-se suas causas, desde o início do período vegetativo até o final do reprodutivo, adaptando-se para tanto, o método descrito por Harcourt (1970). Para evitar a transmissão por contato da virose viracabeça do tomateiro, as plantas infectadas foram retiradas e anotadas como plantas mortas por virose. Foram avaliados o número de flores e frutos/ planta, segundo a metodologia desenvolvida por Chandler (1984). Nas colheitas, os frutos sadios foram contados, pesados e classificados (maior diâmetro transversal do fruto), segundo norma adaptada do Ministério da Agricultura (Portaria $\mathrm{n}^{\circ} 553 \mathrm{MA}$, publicado no DOU de 19/09/95), considerando-se Graúdo AA (=69,6 mm), Graúdo A $(=60,0$ e $<69,6 \mathrm{~mm})$, Médio extra $(=54,8$ e $<60,0 \mathrm{~mm}$ ), Médio especial $(=50,0$ e $<54,8 \mathrm{~mm}$ ), Pequeno (=40,0 e $<50,0$ $\mathrm{mm})$ e Refugo ( $<40,0 \mathrm{~mm})$. Foram considerados frutos comerciais aqueles com diâmetro maior que $40 \mathrm{~mm}$. Foram ainda contados e pesados os frutos danificados, segundo cada causa de perda (Picanço et al., 1997).

A tabela de vida foi feita para cada parcela e construída a partir das médias das parcelas de cada tratamento, conforme metodologia desenvolvida por Picanço (1992), contendo os seguintes componentes: $\mathrm{x}=$ componente de produção da cultura do tomateiro (plantas, flores, frutos totais e frutos colhidos); $\mathrm{Lx}=$ estimativa de produtividade $\mathrm{em} \mathrm{kg} /$ ha de frutos no início de cada $\mathrm{x} ; \mathrm{dxF}=$ fator causador de perdas na produtividade da cultura; $\mathrm{dx}=$ estimativa de perdas na produção da cultura em $\mathrm{kg} / \mathrm{ha}$ de frutos; $100 \mathrm{qx}=$ percentagem de perdas não acumulativas e $100 \mathrm{rx}=$ percentagem de perdas acumulativas.

A estimativa dos Lx foi realizada da seguinte maneira: Lx (planta) $=\mathrm{Pl}$ x Fl/ Pl x Pfr; Lx (flores)= Plc x Fl/Pl x Pfr; $\mathrm{Lx}($ frutos totais $)=\mathrm{Plc} \times \mathrm{Frt} / \mathrm{Pl} \times \mathrm{Pfr} ; \mathrm{Lx}$ $($ frutos colhidos $)=\mathrm{Plc} \times \mathrm{Frc} / \mathrm{Pl} \times \mathrm{Pfr}$; sendo: $\mathrm{Pl}=$ número médio de plantas/ha no início do cultivo; $\mathrm{Fl} / \mathrm{Pl}=$ número total de flores/planta; $\mathrm{Pfr}=$ peso médio dos frutos em $\mathrm{kg} ; \mathrm{Plc}=$ número médio de plantas nas colheitas/ha; Frt/Pl= número médio de frutos totais/planta e Frc/ $\mathrm{Pl}=$ número médio de frutos sadios colhidos/planta.

Para a determinação do componente crítico de perdas e do fator-chave de perdas para a cultura foi utilizado o modelo desenvolvido por Varley e Gradwell (1960), modificado por Picanço (1992), para estudo em tabelas de vida de culturas. Para tanto, foram utilizados os dados provenientes das tabelas de vida de cada parcela, contendo os seguintes componentes: $\mathrm{x}=$ componente de produção da cultura; $\mathrm{Lx}=$ estimativa de produtividade $\mathrm{em} \mathrm{kg} / \mathrm{ha}$ de frutos no início de cada $\mathrm{x} ; \log (\mathrm{Lx})=$ logaritmo decimal dos valores de Lx; $\mathrm{k}=$ perdas específicas [obtidas por subtração de cada valor de $\log (\mathrm{Lx})$, do valor que lhe precede] e $\mathrm{K}=$ perdas totais (obtida pelo somatório dos valores de $\mathrm{k}$ ).

Foram calculados os coeficientes de correlação de Pearson entre as perdas específicas $(\mathrm{k})$ e totais $(\mathrm{K})$, sendo considerados como componentes críticos de perdas na produção aqueles cujas flutuações das perdas específicas apresentaram correlações significativas com a flutuação de perdas totais (Faleiro et al., 1995). A análise de regressão foi utilizada como critério auxiliar na identificação do componente crítico de perdas quando as perdas de duas fases apresentaram correlação significativa $(P<0,01)$ com as perdas totais. O componente de produção, cuja curva de regressão apresentou maior coeficiente angular, foi considerado como componente crítico de perda (Podoler e Rogers, 1975).

Para se determinar o fator-chave de perdas da cultura, foram utilizados os 
R. A. Loos et al.

Tabela 1. Tabela de vida do tomateiro 'Sta. Clara I 5300'. Os valores representam a média das parcelas. Viçosa (MG), UFV, 2001.

\begin{tabular}{|c|c|c|c|c|c|}
\hline Componente de produção (x) & $\begin{array}{c}\text { Estimativa de } \\
\text { produtividade } \\
\text { (t/ha) (Lx) }\end{array}$ & $\begin{array}{l}\text { Fator causador de } \\
\text { perdas }(\mathrm{dxF})\end{array}$ & $\begin{array}{c}\text { Perdas na } \\
\text { produtividade } \\
\text { (t/ha) (dx) }\end{array}$ & $\begin{array}{c}\text { Perdas não- } \\
\text { acumulativas (\%) } \\
\text { (100qx) }\end{array}$ & $\begin{array}{c}\text { Perdas } \\
\text { acumulativas (\%) } \\
(100 \mathrm{rx})\end{array}$ \\
\hline Plantas (fase vegetativa) & 75,81 & - & - & 0,00 & 0,00 \\
\hline Plantas (fase reprodutiva) & 75,81 & TSWV & 7,10 & 9,37 & 9,37 \\
\hline Flores & 68,71 & Abortamento & 3,16 & 4,60 & 4,17 \\
\hline \multirow[t]{10}{*}{ Frutos totais } & 65,55 & Podridão apical & 13,75 & 20,98 & 18,14 \\
\hline & & $\begin{array}{l}\text { Neoleucinodes } \\
\text { elegantlis }\end{array}$ & 4,68 & 7,13 & 6,17 \\
\hline & & Erwinia carotovora & 0,97 & 1,49 & 1,29 \\
\hline & & Rachaduras & 1,45 & 2,20 & 1,91 \\
\hline & & Tuta absoluta & 0,15 & 0,22 & 0,19 \\
\hline & & Alternaria solani & 3,61 & 5,51 & 4,76 \\
\hline & & Pássaros & 1,04 & 1,58 & 1,37 \\
\hline & & $\begin{array}{l}\text { Phytophthora } \\
\text { infestans }\end{array}$ & 0,09 & 0,14 & 0,12 \\
\hline & & refugo & 0,41 & 0,62 & 0,53 \\
\hline & & & 26,14 & 39,88 & 48,02 \\
\hline Frutos colhidos & 39,41 & & 36,40 & & 48,02 \\
\hline
\end{tabular}

Tabela 2. Tabela de vida do tomateiro ‘Débora Plus'. Os valores representam a média das parcelas. Viçosa (MG), UFV, 2001.

\begin{tabular}{|c|c|c|c|c|c|}
\hline Componente de produção $(x)$ & $\begin{array}{c}\text { Estimativa de } \\
\text { produtividade } \\
\text { (t/ha) (Lx) }\end{array}$ & $\begin{array}{l}\text { Fator causador de } \\
\text { perdas }(\mathrm{dxF})\end{array}$ & $\begin{array}{c}\text { Perdas na } \\
\text { produtividade } \\
\text { (t/ha) (dx) }\end{array}$ & $\begin{array}{c}\text { Perdas não- } \\
\text { acumulativas (\%) } \\
(100 q x)\end{array}$ & $\begin{array}{c}\text { Perdas } \\
\text { acumulativas (5) } \\
(100 \mathrm{rx})\end{array}$ \\
\hline Plantas (fase vegetativa) & 75,12 & - & - & 0,00 & 0,00 \\
\hline Plantas (fase reprodutiva) & 75,12 & TSWV & 15,45 & 20,57 & 20,57 \\
\hline Flores & 59,67 & Abortamento & 2,33 & 3,91 & 3,10 \\
\hline \multirow[t]{11}{*}{ Frutos totais } & 57,34 & Podridão apical & 15,14 & 26,40 & 20,15 \\
\hline & & $\begin{array}{l}\text { Neoleucinodes } \\
\text { elegantlis }\end{array}$ & 3,72 & 6,49 & 4,95 \\
\hline & & Erwinia carotovora & 0,70 & 1,22 & 0,93 \\
\hline & & Rachaduras & 0,76 & 1,32 & 1,01 \\
\hline & & Tuta absoluta & 0,09 & 0,16 & 0,12 \\
\hline & & Alternaria solani & 2,91 & 5,07 & 3,87 \\
\hline & & TSWV & 0,19 & 0,32 & 0,25 \\
\hline & & Pássaro & 0,82 & 1,43 & 1,09 \\
\hline & & $\begin{array}{l}\text { Phytophthora } \\
\text { infestans }\end{array}$ & 0,11 & 0,20 & 0,15 \\
\hline & & Refugo & 0,55 & 0,95 & 0,73 \\
\hline & & & 24,98 & 43,57 & 56,93 \\
\hline Frutos colhidos & 32,36 & & & & 56,93 \\
\hline
\end{tabular}

componentes: $\mathrm{dxF}=$ fator causador $\mathrm{de}$ perdas na produtividade da cultura; $\mathrm{Lx}=$ estimativa de produtividade $\mathrm{em} \mathrm{kg} / \mathrm{ha}$ de frutos no início de cada $\mathrm{x}$, subtraída a perda causada por cada fator; $\log (\mathrm{Lx})=$ logaritmo decimal dos valores de Lx; $\mathrm{k}=$ perdas específicas; e $\mathrm{K}=$ perdas totais do componente de produção em questão (Picanço et al., 1998). 


\section{RESULTADOS E DISCUSSÃO}

Os coeficientes de variação variaram de $11 \%$ para a produtividade comercial ('Santa Clara': 39,34 t/ha e 'Débora Plus': 35,03 t/ha) a $29 \%$ para a produtividade de frutos graúdos, sendo que as fontes de variação não foram significativas, indicando não haver diferença entre tratamentos, exceto para frutos graúdos A ('Santa Clara': 13,24 t/ha e 'Débora Plus': 6,16 t/ha). Esta diferença é comercialmente importante, visto que frutos maiores têm melhor preço no mercado. As produtividades de frutos 'Santa Clara' e 'Débora Plus' de classificação médio extra foram 7,38 e 6,35 t/ha e médio especial juntamente com pequeno totalizaram 18,72 e 22,52 t/ha, respectivamente. Foi observada baixa produtividade comercial em comparação à produtividade nacional (55 t/ha), tanto para a cultivar Sta. Clara, quanto para o híbrido Débora Plus, com perdas de 36,40 t/ha e 42,76 t/ha, correspondendo às perdas cumulativas totais de $48,02 \%$ e $56,93 \%$, respectivamente (Tabelas 1 e 2).

Não houve perdas na fase vegetativa (Tabelas 1 e 2). Na fase reprodutiva, a ocorrência do TSWV causou mortalidade de plantas nos dois tratamentos, gerando perdas médias de 7,10 t/ha na cultivar Sta. Clara (Tabela 1) e 15,45 t/ha no híbrido Débora Plus (Tabela 2). O principal inseto-vetor desta virose é o tripes Frankliniella schultzei Trybom (Thysanoptera: Thripidae) pelas características de polifagia, facilidade de reprodução, número de ovos produzidos e capacidade de difusão rápida na natureza. No entanto, a transmissão por contato e através de tratos culturais também ocorre (Sinigaglia et al., 2000).

A perda no componente de produção flores foi considerada como abortamento (Tabelas 1 e 2), podendo ter ocorrido pela não-fecundação dos óvulos (Kinet e Peet, 1997).

A fase reprodutiva foi a fase onde ocorreu a mortalidade de plantas, sendo, o ataque do vírus TSWV o único fator causal de tais perdas. Os componentes de produção que regularam, significativamente, a flutuação de perdas totais foram plantas (fase reprodutiva)

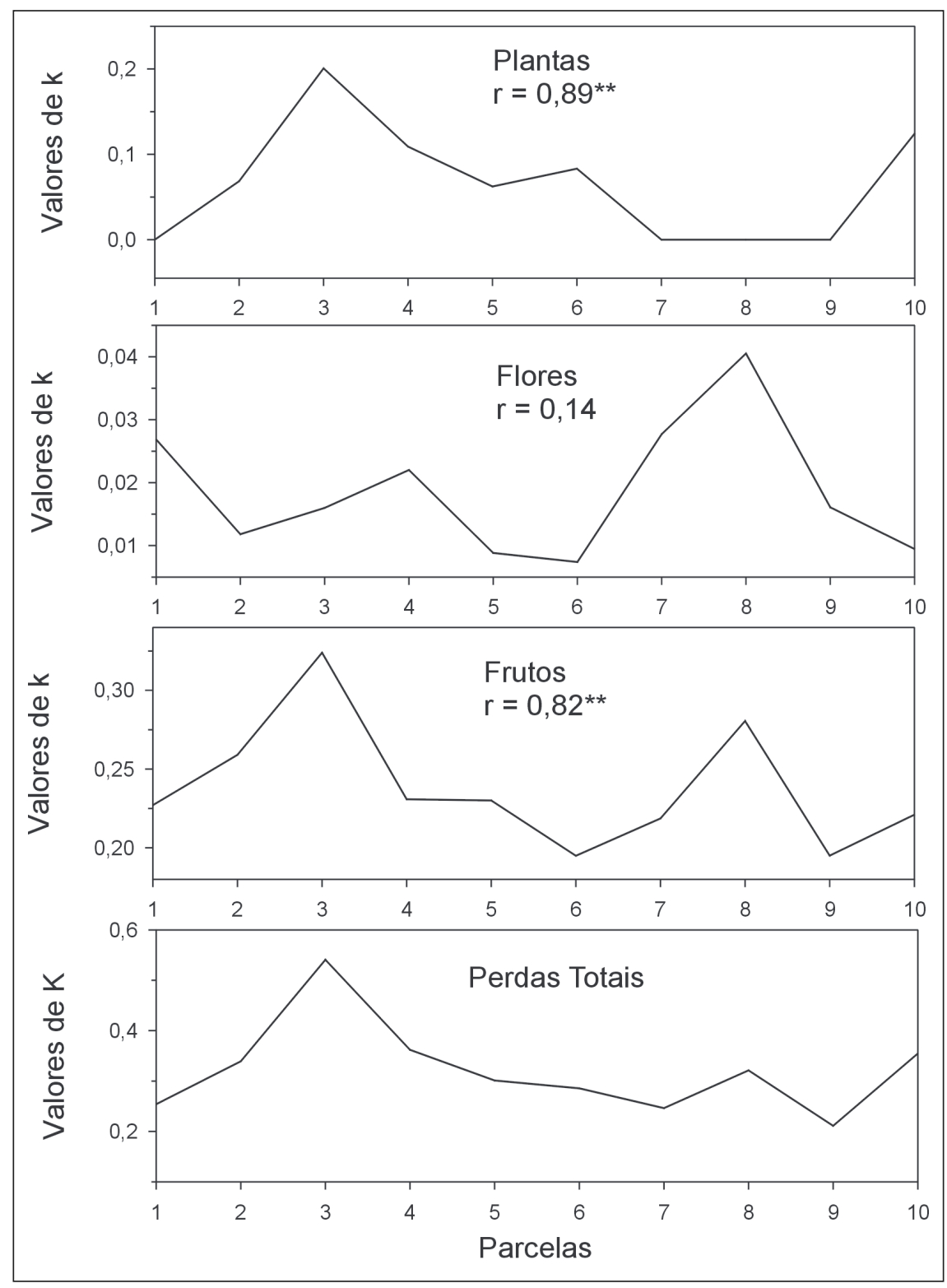

Figura 1. Flutuações das perdas parciais $(\mathrm{k})$ e totais $(\mathrm{K})$ dos componentes de produção do tomateiro nas parcelas dos tratamentos do híbrido Débora Plus (Parcelas 1 a 5) e da cultivar Sta. Clara I 5300 (Parcelas 6 a 10) $(* * P<0,01)$. Viçosa (MG), UFV, 2001.

$(\mathrm{r}=0,89 ; P<0,01)$ e frutos $(\mathrm{r}=0,82$; $P<0,01$ ) (Figura 1). No entanto, pela análise de regressão, utilizada como critério auxiliar na identificação do componente crítico de perdas da produção, constatou-se que o componente de produção plantas foi o componente crítico de perdas por apresentar maior coeficiente de inclinação da curva (Figura 2). As perdas no componente de produção frutos foram por podridão apical, Neoleucinodes elegantalis, Erwinia carotovora, rachamento, Tuta absoluta, Alternaria solani, TSWV, pássaros, Phytophthora infestans e tamanho nãocomercial dos frutos (refugo). Picanço et al. (1998), ao avaliarem as perdas na produção do tomateiro cultivado com diferentes espaçamentos e aplicações de inseticidas, e Paula (1997), ao determinar os fatores de perdas no tomateiro, verificaram a ocorrência dos mesmos fatores supracitados causadores de perdas nos frutos, além de Helicoverpa zea e queda de frutos. Os resultados demonstram a importância de se direcionar o manejo adequado para esses tipos de perdas. No caso de Phytophthora infestans, a ocorrência limitou-se ao final do ciclo da cultura e em baixa intensidade.

As perdas no componente de produção plantas na cultivar Sta. Clara (Tabela 1) e 


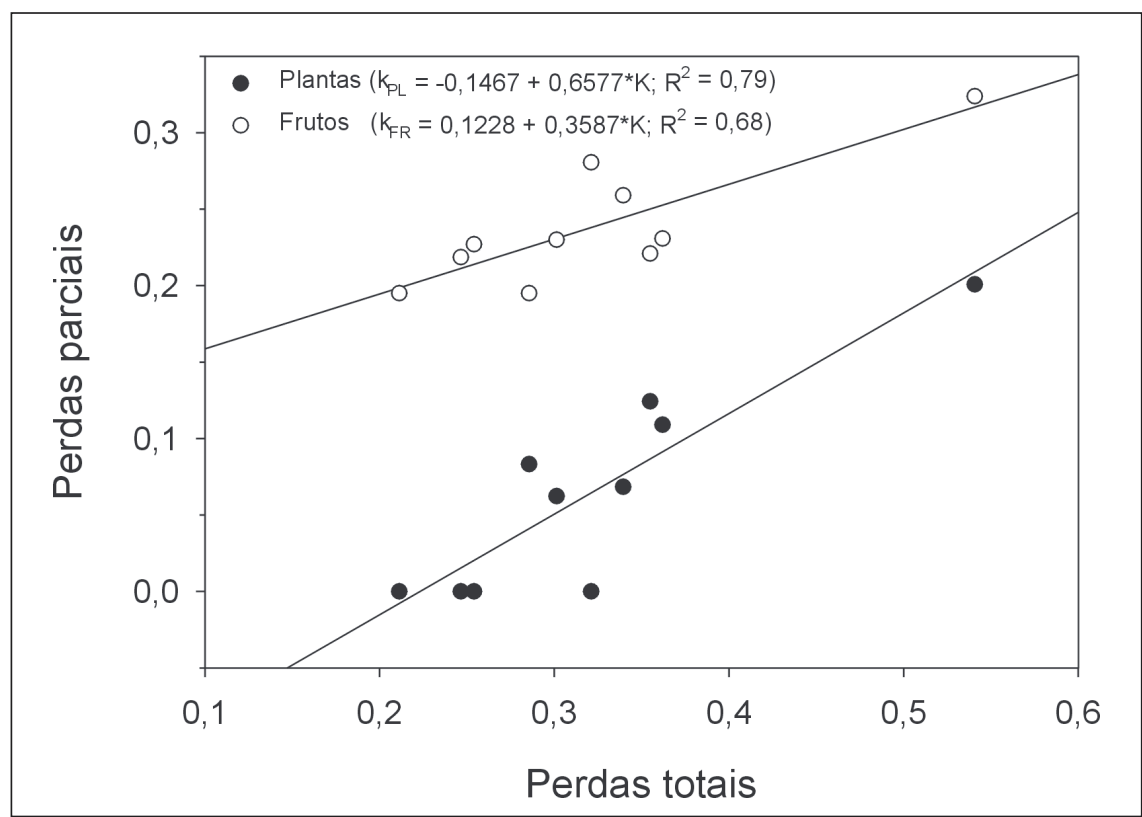

Figura 2. Curvas de regressão entre perdas parciais (k) e totais (K) dos componentes de produção da cultura do tomateiro que apresentaram correlação significativa com perdas totais de produção $(* P<0,05)$. Viçosa $(\mathrm{MG}), \mathrm{UFV}, 2001$.

no híbrido Débora Plus (Tabela 2) foram causadas por TSWV, sendo considerado como fator-chave de perda da produção. As perdas médias ocasionadas por TSWV foram 7,10 t/ha para 'Sta. Clara' e 15,45 t/ha para 'Débora Plus', inferiores ou semelhantes às perdas médias causadas por podridão apical, que foram $13,75 \mathrm{t} / \mathrm{ha}$ para 'Sta. Clara' $\mathrm{e}$ 15,14 t/ha para 'Débora Plus'. Apesar de sua magnitude, as perdas por podridão apical não se constituíram em fator-chave de perdas, devido a sua incidência ter sido constante nas diversas parcelas, não influenciando a flutuação de perdas totais.

O desenvolvimento de estratégias ótimas para controle de perdas na produtividade do tomateiro requer um reconhecimento seguro das ações e interações dos diferentes fatores de perda da cultura. Uma ou duas tabelas de vida revelarão somente que as perdas severas na produ- ção podem ocorrer em determinados intervalos do ciclo da planta, mas uma série de tabelas, repetidas apropriadamente no tempo e no local, fornecerá diretrizes úteis ao planejamento de estratégias de controle de perdas, particularmente quando acoplada com análises de custobenefício.

\section{AGRADECIMENTOS}

Ao CNPq pela concessão da bolsa de estudos de mestrado.

\section{LITERATURA CITADA}

BERGAMIM FILHO, A.; KIMATI, H.; AMORIM, L. Manual de fitopatologia. 3. ed. São Paulo: Ceres, 1995. 919 p, 2 v.

CAMARGOS, M.I. Produção e qualidade de tomate longa vida em estufa, em função do espaçamento e do número de cachos por planta. Viçosa: UFV, 1998. 68 p. (Tese mestrado).

CHANDLER, L. Crop life table studies of the pests of beans (Phaseolus vulgaris L.) at GoiâniaGO. Revista Ceres, Viçosa, v.31, n.176, p.284-298, 1984.

FALEIRO, F.G.; PICANÇO, M.C.; GUEDES, R.N.C.; MIRANDA, M.M.M.; ARAÚJO, J.M. Intensidade de perdas em 49 populações de milho (Zea mays L.) cultivadas em condições de baixa tecnologia. Revista Ciência e Prática, v.19, n.3, p.272-280, 1995.

HARCOURT, D.G. Crop life tables as a pest management tool. Canadian Entomologist, v.102, n.8, p.950-955, 1970.

KINET, J.M.; PEET, M.M. Tomato. In: WIEN, H.C., ed. The physiology of vegetable crops. Wallingford: Commonwealth Agricultural Bureau (CAB) International, 1997. p.207-258.

OLIVEIRA, V.R. Número de ramos por planta, poda apical e época de plantio influenciando a produção e a qualidade dos frutos de tomateiro (Lycopersicon esculentum Mill) cv. Kada. Viçosa: UFV, 1993. 114 p. (Tese mestrado).

PAULA, S.V. Incidência de pragas e reflexos na produção do tomateiro em função da adoção de nivel de controle e de faixas circundantes. Viçosa: UFV, 1997. 90 p. (Tese mestrado).

PICANÇO, M.C. Entomofauna e danos das pragas associadas à cultura de ervilha (Pisum sativum L.), em quatro épocas de plantio e 54 cultivares. Viçosa: UFV, 1992. 310 p. (Tese doutorado).

PICANÇO, M.; FALEIRO, F.G.; PALLINI FILHO, A.; MATIOLI, A.L. Perdas na produtividade do tomateiro em sistemas alternativos de controle fitossanitário. Horticultura Brasileira, Brasília, v.15, n.2, p.88-91, 1997.

PICANÇO, M.; LEITE, G.L.D.; GUEDES, R.N.C.; SILVA. E.A. Yield loss in trellised tomato affected by insecticidal sprays and plant spacing. Crop Protection, v.17, n.5, p.447-452, 1998.

PODOLER, H.; ROGERS, D. A new method for the identification of key-factors from life-table data. Journal of Animal Ecology, n.44, p.85-114, 1975. SILVEIRANETO, S.; NAKANO, O.; BARBIN, D.; VILLA NOVA, N.A. Manual de ecologia dos insetos. São Paulo: Agronômica Ceres, 1976. 419 p. SINIGAGLIA, C.; RODRIGUES NETO, J.; COLARICCIO, A.; VICENTE, M.; GROPPO, G.A.; GRAVENA, S.; LEITE, D. Manejo integrado de pragas e doenças do tomateiro. v.6, São Paulo: Secretaria de Agricultura e Abastecimento, $2000.66 \mathrm{p}$.

ULLMAN, D.E.; SHERWOOD, J.L.; GERMAN, T. Thrips as vectors of plant pathogens. In: LEWIS, T., ed. Thrips as crop pests. New York: CAB International, 1997. 736 p.

VARLEY, G.C.; GRADWELL, G.R. Key factors in population studies. Journal of Animal Ecology, v.29, n.2, p.399-401, 1960. 